\title{
Start-up failures due to Quality Failures
}

\author{
Saadullah Aleem \\ Institute of Business Administration, Karachi, 75270, Pakistan \\ E-mail: saadullah.aleem@khi.iba.edu.pk
}

\section{Santosh}

Institute of Business Administration, Karachi, 75270, Pakistan

E-mail: santosh.14888@khi.iba.edu.pk

\author{
Waqas Mahmood \\ Institute of Business Administration, Karachi, 75270, Pakistan \\ E-mail: wmehmood@iba.edu.pk
}

Received: 19 January 2021; Accepted: 12 March 2021; Published: 08 April 2021

\begin{abstract}
Software start-ups are fundamentally different from traditional software development firms and boutique software services enterprises of all sizes. They develop software products with strict time and resource constraints and are focused on beating competitors to the market. They fail fast and often pivot their business models several times in their lifetimes. Their approach to designing, developing, testing, and shipping software products differs vastly from the established software engineering principles that emerged during the field's earlier decades. One such principle is Software Quality Assurance. Start-ups tend to do away with procedures that ensure that their products are of the utmost quality. Instead, they focus on shipping their products to market as fast as possible, testing these products vis-a-vis reallife customers and use-cases, and eventually improving these products, repeating the process several times over. We hypothesize that this reluctance to adhere to software quality assurance principles can have adverse effects on the health of start-ups or their products. This paper investigates this hypothesis through over 20 questions presented to CEOs, CTOs, Technical Leads, and Product Managers of several start-ups. These questions focus on start-ups' motivations, their levels of understanding and appreciation of software quality assurance principles, and the limitations they face due to time and resource constraints. Our research's results indicate the surveyed start-ups' problems are partially due to the absence of robust software quality assurance practices within their processes.
\end{abstract}

Index Terms: Software Quality Assurance, Start-ups, Software Engineering, SQA practices

\section{Introduction}

The start-up industry has shown significant growth in the last two decades. Pakistani start-ups alone raised 18 Million Dollars during the nation-wide Coronavirus lockdown [1].

As compared to the high-profile organizations and software development companies, the new start-ups face more problems in integration and ensuring the software's quality. Those problems are the lack of human resources, investment constraints, time issues, and others [4]. Traditional software engineering and quality assurance practices are deemed unfit for fast-changing requirements, which have resulted in their evolution [6]. Software start-ups work under immense uncertainty and pivot their product frequently and as needed [7].

Furthermore, start-up founders tend to focus on more important factors, which result in Software Quality Assurance practices' deliberate disregard. IBM has published a whitepaper comparing the costs of discovering an error at different development lifecycle stages. The multipliers are 5x for the implementation phase, 10x for integration testing, and 30x after the product's release to the market [5].

We found very rare research has been conducted on Software Quality Assurance (SQA) related issues for start-ups in the software industry, the software been a fastly growing industry specifically in Pakistan, which opens up a variety of topics to be researched. Our research investigates the role of Software Quality Assurance best practices within the fast-growing tech start-up ecosystem. Our research also focused on the impact of poor software quality practices on product and software failure. Our research paper analyses the SQA practices in the startup industry and helps in determining the reasons that result in software testing practices being overlooked by start-ups [3]. 


\section{Background}

The growth of start-ups has been motivated by many reasons, with job-security being the most important one. It has become evident during the COVID-19 pandemic due to downsizings.

Internet start-ups deliver technological (software) products to businesses and individuals. Being a newly launched firm, a start-up goes through multiple development phases to gain trust and name in the market, having limited personnel and resources.

During their development phases, the internet and software start-ups have to go through multiple challenges. The two most common are the software's quality and the extremely short time-to-market, which is in weeks or months [2].

In the pressure of getting the products to the market ahead of the competitors, the start-ups consider quality assurance a less essential component of software development, which leads to frequent mishaps because of software failure or errors $[18,19]$.

Our research analyzes the problems faced by the software start-ups that are caused by the lack of adherence to the software quality assurance practices. The research aims to achieve this goal by the literature and a survey conducted from the people having crucial roles in the software start-ups having a limitation of a small population belonging to this category. Similarly, it is perceived that most start-up lack standard practices and frameworks [22].

This study investigates the extent to which start-ups' failures can be attributed to failure to adhere to software quality assurance principles. Addressing these gaps can be significant as it could help start-up founders and leaders understand quality failures and work towards building more robust software products.

Moreover, we intend to validate the hypothesis that start-ups tend to mutate - often to disastrous effects - SQA tools and procedures to fit them into their inconstant software development goals.

\section{Literature Review}

There is little literature solely focused on software quality assurance practices in software start-ups. Most researchers tend to focus on the subject of software engineering when researching software start-ups and their operations.

Software quality assurance can become expensive in calendar time [10,11] and is mostly absent in software startups. Other reasons include a lack of experience amongst the start-up personnel [8] and weak methodological management [9]. Start-ups usually rely on usability tests to achieve product-market-fit [12,13,14]. Mater and Subramanian suggest focusing on a relatively smaller group of early adopters to drive their product's quality assurance aspect [2]. Thus, removing bugs and adding more tests can be done if the early adopters run into issues with the software. This approach is different from traditional quality assurance practices [11].

Start-ups also outsource their testing work to software testing experts on an as-needed basis, often due to the lack of resources, as mentioned earlier. This outsourcing helps in focusing their resources on the development of core functionalities of their product. Communcation problems can exist between distributed teams [20].

Start-ups often ignore standard software quality assurance methodologies because they are mostly incompatible with lean start-up methodologies that most software start-ups practice for SQA in developing countries [17,21].

Technical debt management is universally harder for software start-ups than it is for traditional software firms. The software market changes rapidly. Thus, start-ups have to pivot multiple times in their lifetimes and often make snap decisions during smaller sprints and development life-cycles [8]. Failure to successfully manage technical debt contributes significantly to start-up failure.

The absence of standard quality assurance practices and established software engineering practices, in general, can also lead to inadequate software quality and, ultimately, start-up failure [15]

The development of software in start-ups is product-oriented. The earlier success becomes irrelevant in the later stages of the product development of a start-up's because the software becomes increasingly complex, resulting in deterioration of performance $[15,16]$

In summary, the following table illustrates start-up failure reasons and causes behind them.

Table 1. Reasons and causes of the start-up failure

\begin{tabular}{|c|l|ll|l|}
\hline \multicolumn{1}{|c|}{ Reason } & & \multicolumn{1}{c|}{ Causes } & Outcome \\
\hline 1. & $\begin{array}{l}\text { Start-ups' inability to adhere to } \\
\text { established software engineering } \\
\text { practices. }\end{array}$ & $\begin{array}{l}1 . \\
2 .\end{array}$ & $\begin{array}{l}\text { Expensive [10] } \\
\text { Weak methodological management [9] } \\
\text { Lack of training of involved personnel [8] }\end{array}$ & Eventual software failure \\
\hline 2. & $\begin{array}{l}\text { Inadequate technical debt } \\
\text { management [8] }\end{array}$ & $\begin{array}{l}1 . \\
2 .\end{array}$ & $\begin{array}{l}\text { Rapidly changing software market. } \\
\text { Multiple pivots in start-ups' lifecycle. }\end{array}$ & Eventual complexity within \\
the product [15]
\end{tabular}




\begin{tabular}{|l|l|ll|l|}
\hline 3. & $\begin{array}{l}\text { Outsourcing of software quality } \\
\text { assurance related tasks }\end{array}$ & $\begin{array}{l}1 . \\
2 .\end{array}$ & $\begin{array}{l}\text { Need to focus on core software development tasks. } \\
\text { Inadequate skills of involved personnel. }\end{array}$ & $\begin{array}{l}\text { Inadequate software quality } \\
\text { infrastructure within the } \\
\text { start-up }\end{array}$ \\
\hline
\end{tabular}

\section{Research Methodology}

Our research tactic is developed and directed using qualitative research methodologies. The qualitative research method is popular to derive and explore start-ups' social, cultural, and economic aspects. The qualitative research approaches play a vital role in comprehending a field's insights and the diversities among that field's contents. This research is a survey-oriented study that includes answers given to the questionnaire and face-to-face interviews where participants answer various questions.

Our research survey aims to determine the software quality assurance practices in Pakistani software start-ups. It seeks to understand the software testing methodologies used, the criteria for selecting an appropriate method based on time and personnel constraints, and the development and testing teams' relations. Additionally, this survey can suggest future research directions for the software quality assurance field vis-a-vis start-ups. The questionnaire of the study is segmented and defined based on hypotheses derived from the literature review.

The survey's participants were individuals working at different positions in different departments of the software start-ups as they contribute to the software development, quality assurance, and overall performance of the enterprise. Due to a small number of software start-ups in Pakistan, we could only perform the study is on a limited number of participants. The participant rate is low, but it covers diverse roles of the software development ventures. As noticeable through figure 1, around half of the survey participants have their functions as Technical leads/senior software engineer, whose perspectives are critical as they directly contribute and stake in the software development process. The other four important roles of the research contributors are Chief Technical Officers, Product Designers, SQA/Test Engineers, and Product Managers /Owners. Looking at the roles of the participants of the study, it can be implied that the sample signifies the study's targeted population.

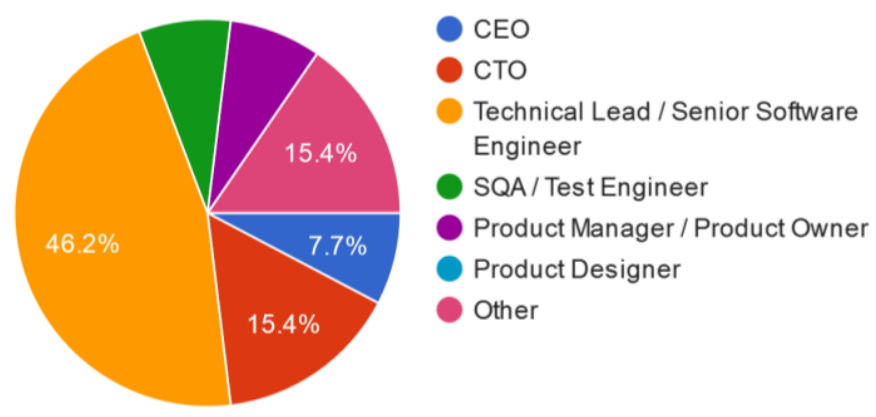

Fig.1. Participants of the survey

\section{V. Survey Results}

\subsection{Characterization}

This section represents the numeric and quantitative details of the software start-ups in Pakistan. Firstly, the research participants were asked about the time their start-up firms have been in service. Figure 2 shows that all the participants' firms have ages of up to 5 years; the majority of the start-ups have been established around 2-5 years ago while $23 \%$ have been present in the industry for less than a year. It shows the growth of the start-ups in the Pakistani technology industry in the last few years, particularly during the Covid-19 pandemic.

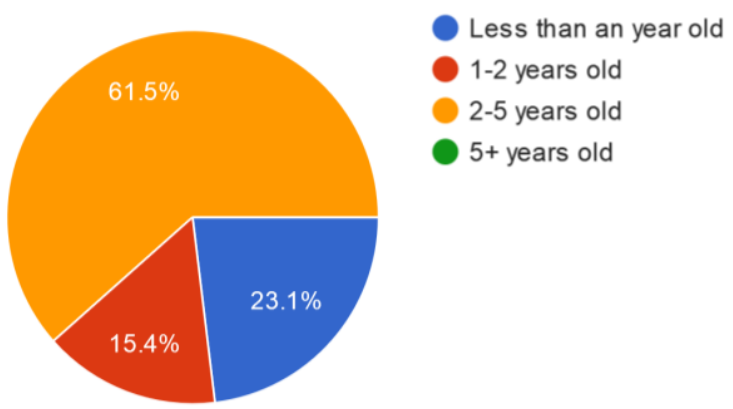

Fig. 2. Age of the start-ups (of the participants) 
Secondly, the participants were asked about the development phase that their start-up firm is in. It was found that $77 \%$ of firms are independently offering their services in the market. Around $15 \%$ of those start-ups are in their initial development phase, approximately $7 \%$ of the start-ups have ceased operation, while none of them has been acquired by another company as apparent in figure 3.

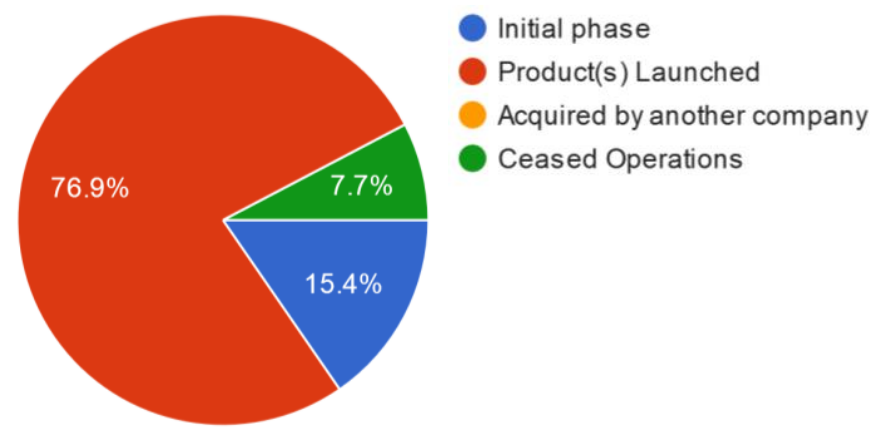

Fig. 3. The development phase of the start-ups (of the participants)

The third question's purpose was to get an insight into the employee size and resources that the start-ups possess. As visualized in figure 4, the study found that around one-fourth of the participants' are working in start-ups having less than ten employees. The percentage remains the same at around 30\% for the number of start-ups having 10-25 employees and 25-50 employees, while around 15\% of the start-ups have more than 50 employees in their firms. The number of employees in these firms has been increasing with time.

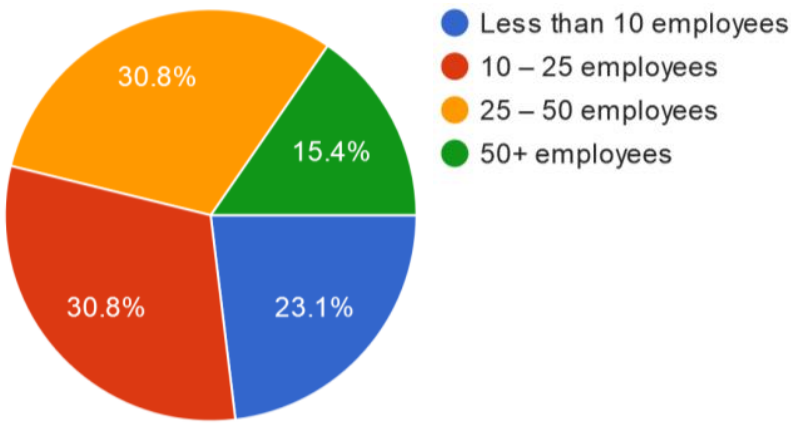

Fig. 4. Number of employees in the start-ups

\subsection{Documentation}

This section of the study aimed to determine whether the start-ups documented their business processes, codes, and several software development steps. Figure 5 tells us that $37 \%$ of start-ups have either not documented any part of their codebase, or have documented one-fourth part of it. There were $30 \%$ of participants working in a start-up that had documented less than or half of their codebase. The percentage remains the same for those having three-fourth part of their code written.

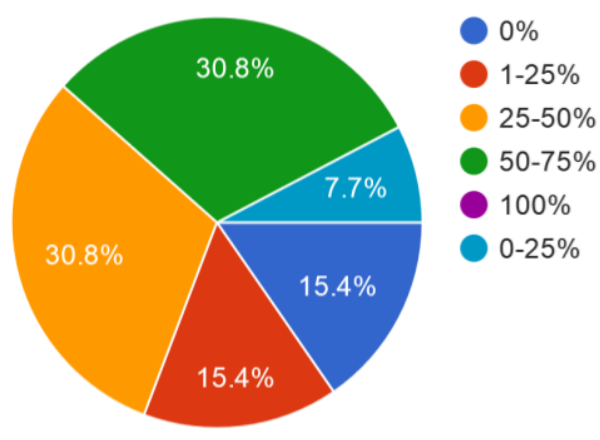

Fig.5. Amount of documented code

In the second question related to the documentation, participants were asked about their start-ups' software components. We found that $15 \%$ of start-ups did not have any of the three, System Architecture, Test plans, and Software Requirement specifications. On the other hand, most of the start-ups performed the System Architecture 
documentation, and the documentation for the test plans and software requirements specification was done by half of them.

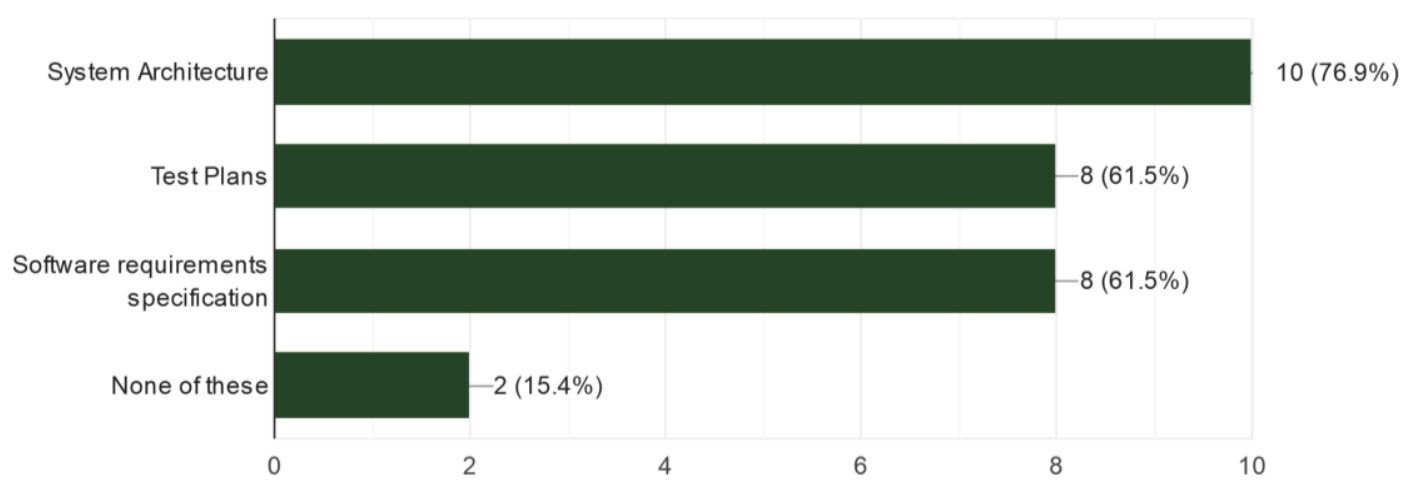

Fig. 6. Types of testing performed in the start-up

\subsection{Software Quality Assurance Practices}

Software quality assurance is a vital part of the software development life-cycle. This statement was supported and accepted by all the participants when they were asked whether they considered Software Quality assurance a critical aspect of Software development. They unanimously answered a yes, as visualized in figure 7.

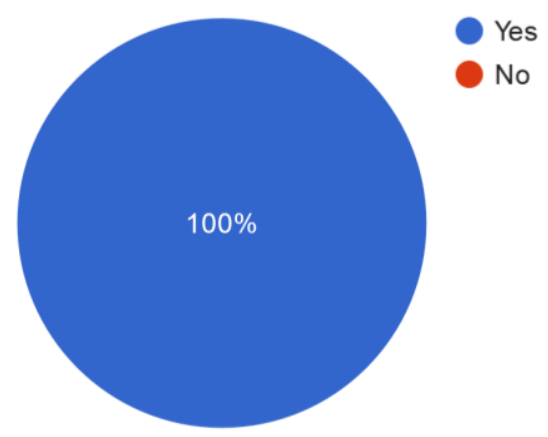

Fig. 7. Participants who consider Software Quality Assurance an important aspect of the software development

This section of the questionnaire aimed to identify the measures and steps taken by the start-ups to maintain the quality of the software products they develop. At first, we asked a question to get the number of start-ups who have a dedicated Software quality assurance department. The Yes to No ratio was $54 \%$ to $46 \%$, as evident in figure 7 . We further noticed that all the start-ups with a dedicated Software Quality Assurance department have been functioning for a longer time and have a higher human resource than those not having it.

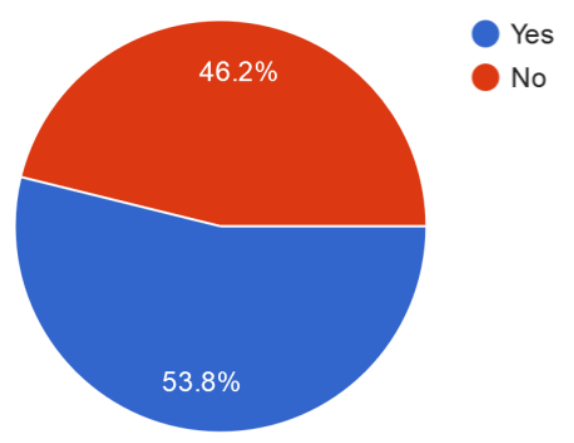

Fig.8. Start-ups having a dedicated Software Quality Assurance Department

The next question was related to the step at which the start-up's software quality assurance team comes on board for testing, troubleshooting, and other quality assurance purposes. As mentioned earlier, a major portion of the respondents said that they don't have a Software Quality Assurance department at their workplaces. Among the respondents having a Software Quality Assurance team, 33\% take the Software Quality Assurance team on board 
during the testing phase. In comparison, the number is $16 \%$ for the start-ups, which involve the software quality assurance team during the initial phase of Requirements Gathering and Analysis. The percentage remains the same at $8 \%$ for the start-ups applying the Software Quality Assurance at the Design, Implementation, and for every phase of the software development life cycle.

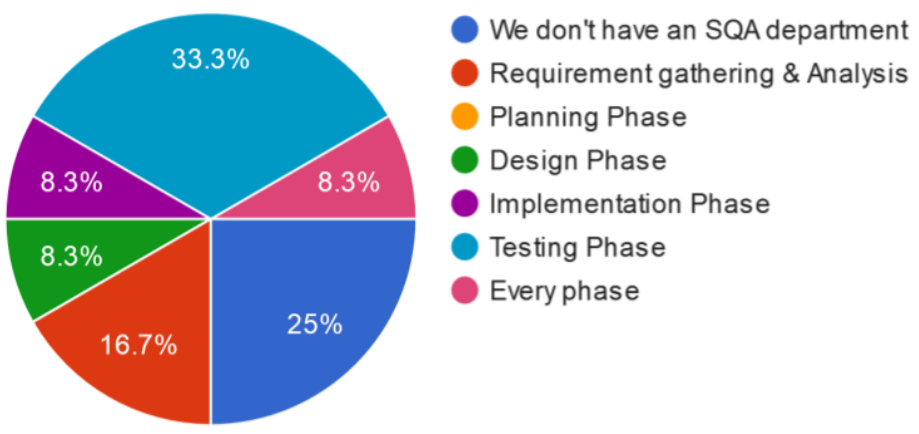

Fig. 9. Step at which the SQA team gets on board

The third question of this section aimed to determine the testing types performed to ensure the software's quality by checking multiple factors. According to the research results as represented in figure 9, 7-8 out of 10 start-ups perform unit tests on their software products. The results show a similar number for the start-ups performing Integration and Functional Tests. 5-6 out of 10 start-ups run the Smoke tests on their software programs. The number is very low for the Automated UI tests performed by only $38 \%$ of the start-ups. The question results also confirm that there was no start-up, which did not perform any software testing. We can further observe that the testing methodology depends on the start-up and its software products' types.

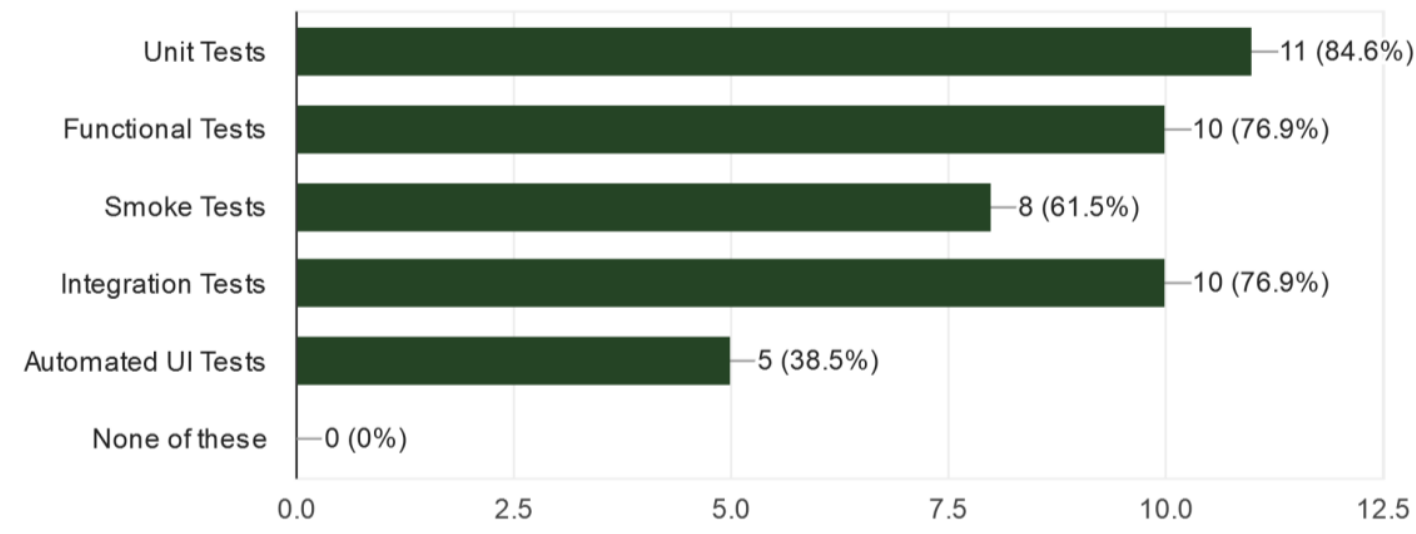

Fig.10. Types of tests performed at the start-ups

The fourth question aimed to get an idea of how many start-ups in Pakistan maintain bugs databases for tracking the issues in their developed software products. Figure 11 shows a 6:4 ratio of the start-ups maintaining bugs database to those not maintaining it. It must be mentioned that the start-ups not maintaining bugs databases will need to repeat through th/e whole process of searching till solving the problems in the softwares.

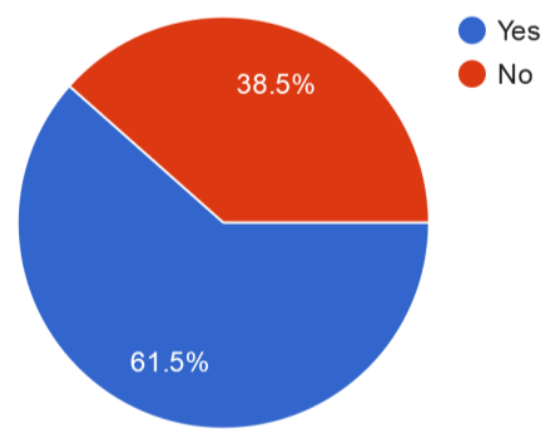

Fig.11. Number of start-ups maintaining a bugs database 
In the next question, the study focused on the bugs that arise after developing the applications. Those bugs' cost is usually higher than pre-release bugs' costs due to the multitudinous installations and other time-consuming efforts. The study found out that around $46 \%$ of the start-ups have $25 \%$ post-release bugs, while the number of start-ups having $25-$ $50 \%$ was $38 \%$ and $50-75 \%$ post-release bugs was around 15\%. It infers that around half of the Pakistani software ventures track the bugs after deploying their software products, which may result in consuming more time and human effort.

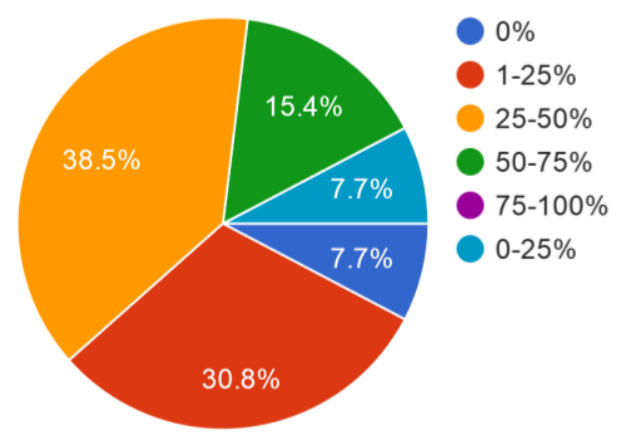

Fig. 12. Percentage of post-release bugs

The results of figure 12 can be related to the results of figure 13. The visualization of the results of the question in which the survey respondents were asked the critical aspect of their ventures. out of 10 respondents chose the option 'Releasing with fewer bugs' while 4 out of 10 selected 'Releasing the software fast.' These numbers can be referred to as the hurry and launch of the products in the fast-paced industry with newly arriving businesses every day.

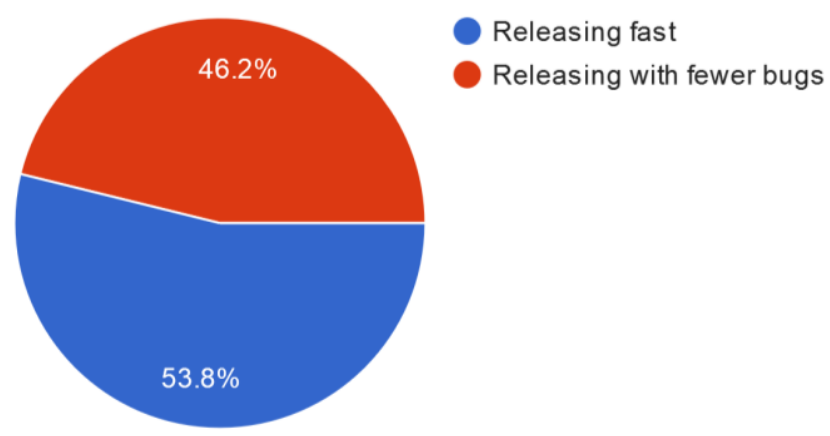

Fig.13. Important task for the start-ups

We further note from figure 14 that 9 out of 10 participants belong to the start-ups which perform their software quality assurance tasks themselves. In comparison, only 1 out of 10 participants belonged to the start-up, which gets their softwares tested through third-party firms.

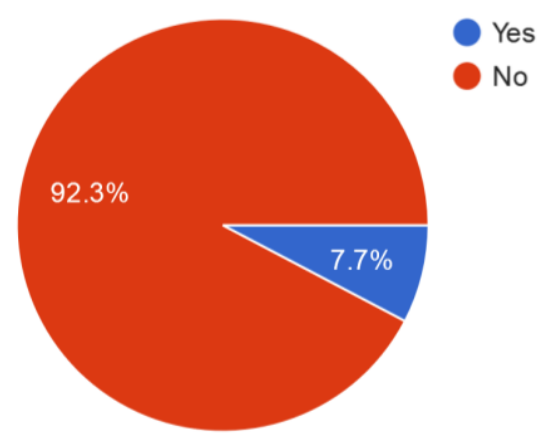

Fig. 14. Start-ups outsourcing the software quality assurance tasks.

\subsection{Challenges due to ignorance of Software Quality Assurance Practices}

The study contains this section to identify the challenges the start-ups face due to the lack of adherence to Software Quality Assurance practices. At first, this section finds out the technical debt caused by the lack of commitment to the Software Quality Assurance principles and practices. This question recognizes the importance of software quality 
assurance in start-ups and the efforts required to redo the tasks appearing faulty in the testings. As figure 15 represents, only $37 \%$ of start-ups don't have about or less than $25 \%$ technical debt due to the lack of software quality assurance practices. On the other hand, the number for those having a high technical debt is more elevated. $23 \%$ of start-ups have $25-50 \%$ technical debt due to not implementing the software quality assurance concepts. Lack of these applications causes $50-75 \%$ technical debt to around $38 \%$ of Pakistan's start-ups.

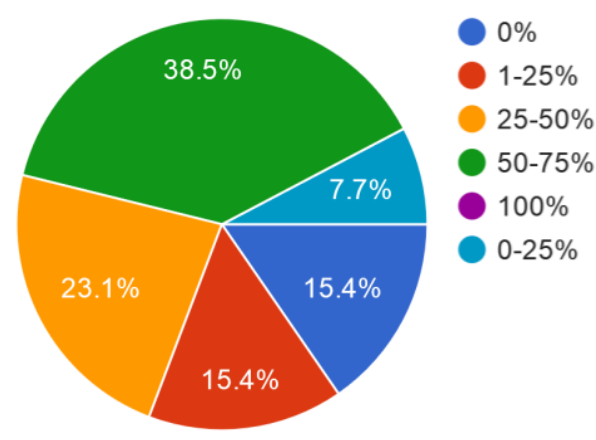

Fig. 15. Percentage of technical debt by a lack of adherence to SQA principles

In the second question, it was found that there has been no financial penalty to the $75 \%$ of participants' start-ups because of the software failures, while $25 \%$ of them have faced it.

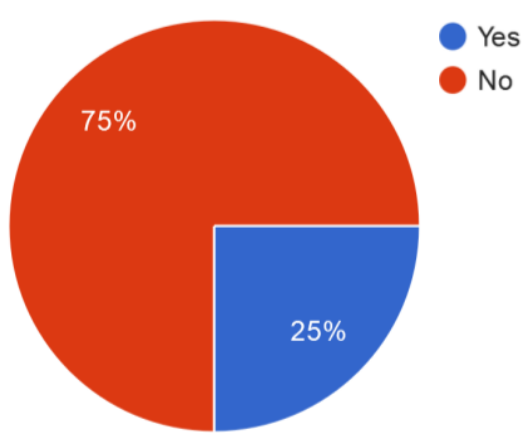

Fig 16. Financial penalty because of software failure

In the third question of this section, the survey respondents were asked if their start-ups scraped any software product because of not meeting the requirements of the product. As shown in figure 17, it didn't occur in $73 \%$ of cases, while $27 \%$ of start-ups destroyed their products because they did not meet the requirements. $27 \%$ is a large percentage considering the human effort, cost, and resources consumed for developing the software. These facts and figures strengthen the concept and importance of the Software quality assurance practices that ensure the products having the required performance, maximum functionalities, and the least number of errors and bugs.

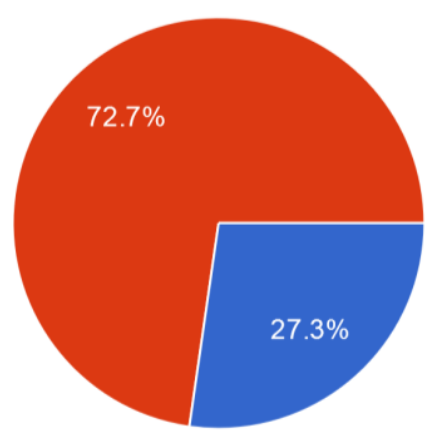

Fig.17. Start-ups that scraped any product because of not meeting the requirements?

The participants themselves further strengthen this statement. There was a $92 \%$ positive response from them when they were asked if they think that whether strictly following the software quality assurance practices will improve their products' life and capability, revenues, and the overall performance and market standing of their ventures. 


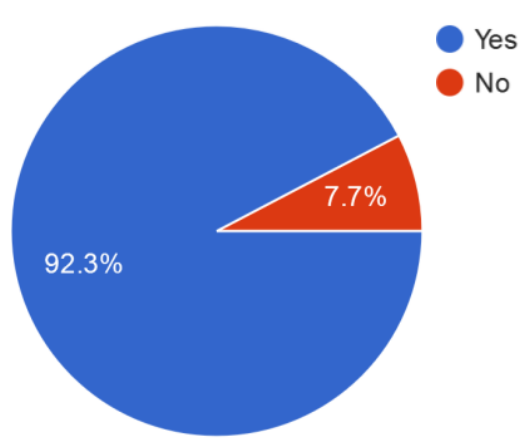

Fig.18. Participants believing that strict adherence to SQA principles would improve the product and revenues of start-up

The survey results highlight the importance of the software quality assurance practices and support the hypothesis of the study that the lack of adherence to the Software Quality Assurance practices leads to several problems that cause a great loss to the image, reputation, and standing of a venture.

\section{Future Work}

Start-ups are an emerging area for research work. As noted in the Literature survey section of the paper, the present literature about software practices in start-ups focuses on the broader aspect of Software Engineering in start-ups. Its focus on Software Quality Assurance is limited. Based upon our findings, future research work could look further into the SQA personnel's role within start-ups and the relationship between technical debt and SQA. Furthermore, it could investigate how certain established Software Quality Assurance principles are mutated and molded to serve Software Start-ups' requirements.

Our research focused mainly on a limited number of Pakistani internet start-ups in which we identified the situations, requirements, industry pace, and other important factors. In the future, this research agenda could be expanded to include a broader array of software start-ups from around the country or the world as operating in different markets could result in various challenges. It can be further detailed to identify the testing methodologies, types of practices, and other SQA options relevant to specific tech-related start-ups. Investigating such difficulties and their impact on Software Quality Assurance could open different research paths.

Due to the nature of the research and the absence of relevant literature, there is still much needed to establish Software Quality Assurance in Software startups as a research area. Abstract concepts in the field require concrete definitions, and further research needs to be conducted to validate our original findings.

\section{Conclusion}

Our research paper highlights the problem faced by software start-ups during their early development phases. The problems were meant to be judged on the hypothesis that the lack of software quality assurance practices is the reason for several hurdles in the way to the progress of the start-ups with limited sources, rush to the market, and other subjective circumstances.

Our analysis's key points indicate the Software Startups understand the importance of traditional Software Quality Assurance principles and the benefits that rigorous adherence to them could bring to Software products. However, the consensus among start-ups is that a stricter commitment to these practices restricts the pace at which these companies operate. The Start-up ecosystem rewards those who are first to the market and fail fast. Unlike a traditional client's business requirements, the requirements of a start-up are not set in stone. For a start-up, involving SQA personnel in the designing, planning, or requirements gathering phase of product development is redundant. Our research found out that the tech-related ventures have been growing significantly specifically during the Covid-19 pandemic. Acceptability of the products of the start-ups which follow the SQA practices and technical debt of the start-ups not adhering to them is the evidence to the hypothesis.

Our findings are significant as they would open new research paths in the developing research area of Software Quality Assurance within start-ups. They can help expand the ways to look at the presented problem by asking subsequent questions based on our research. Software start-ups are diverse both in terms of the people involved and the issues that they focus on solving. The type of solutions being developed and the testing needs of these solutions need to be further investigated.

It should be noted that this research work was not meant to be exhaustive. It hypothesized a problem through anecdotal evidence and performed the necessary investigation on a subset of software start-ups. To develop into a promising significant research area, further contributions are required from researchers of varied backgrounds. 


\section{Annexure}

Survey Questionnaire: The survey questionnaire was self-made for this research. The questions of the survey are. Q1. What is the age of your startup?

- Less than a year old

- 1-2 years old

- 2-5 years old

- 5+ years old

Q2. What is the current status of your startup?

- Initial phase

- $\quad$ Product(s) Launched

- Acquired by another company

- Ceased Operations

Q3. What is the number of employees?

- Less than 10 employees

- $10-25$ employees

- 25 - 50 employees

- 50+ employees

Q4. What is your role in the organization?

- CEO

- CTO

- Technical Lead / Senior Software Engineer

- $\quad$ SQA / Test Engineer

- Product Manager / Product Owner

- Product Designer

- Other

Q5. What percentage of your product and codebase documented?

- $0 \%$

- $1-25 \%$

- $25-50 \%$

- $50-75 \%$

- $100 \%$

Q8. Which of the following are part of your startup's documentation?

- System Architecture

- Test Plans

- Software requirements specification

- None of these

Q9. Is there a dedicated Software Quality Assurance department within your startup?

- Yes

- No

Q10. At what phase does the SQA team become a part of the picture?

- We don't have an SQA department

- Requirement gathering \& Analysis

- Planning Phase

- Design Phase

- Implementation Phase

- Testing Phase

- $\quad$ Every phase 
Q11. Which types of tests are performed in your organization?

- Unit Tests

- Functional Tests

- Smoke Tests

- Integration Tests

- Automated UI Tests

- None of these

Q12. Do you believe that Software Quality Assurance is an important aspect of software development for your startup?

- Yes

- No

Q13. Does your startup maintain a bugs database?

- Yes

- No

Q14. What percentage of your bugs are post-release?

- $0 \%$

- $1-25 \%$

- $25-50 \%$

- $50-75 \%$

- $75-100 \%$

Q15. Which one of these is more important to your startup?

- Releasing fast

- Releasing with fewer bugs

Q16. Does your startup outsource Software Quality Assurance tasks?

- Yes

- No

Q17. What percentage of your technical debt is caused by a lack of adherence to SQA principles?' $0 \%$

- $0 \%$

- $1-25 \%$

- $25-50 \%$

- $50-75 \%$

- $100 \%$

Q18. Has your startup ever faced a financial penalty because of software failure?

- Yes

- No

Q19. Has your startup ever scraped any product because of not meeting the requirements?

- Yes

- No

Q20. Do you believe that stricter adherence to SQA principles would improve the product and the revenues of your startup?

- Yes

- No

\section{References}

[1] The News. "Tech start-ups raise $\$ 18$ million in six months." The News, 1 October 2020, shorturl.at/dACV0. Accessed November 7, 2020.

[2] Mater, J. L., \& Subramanian, B. (2000). Solving the software quality management problem in Internet start-ups. Keynote Address October 17. Chicago

[3] Klotin, E., Gorschek, T., \& Unterkalmsteiner, M. (2018, May 21). Software engineering in start-up companies: An analysis of 88 experience reports. Empirical Software Engineering, 24(1), 68-109. https://doi.org/10.1007/s10664-018-9620-y 
[4] Souza, R., Malta, K., \& Santana De Almeida, E. (2017). Software engineering in start-ups: a single embedded case study. Softstart. https://dl.acm.org/doi/10.5555/3105749.3105756

[5] Briski, K. A., Chitale, P., Hamilton, V., Pratt, A., Starr, B., Veroulis, J., \& Villard, B. (2008, October). Minimizing code defects to improve software quality and lower development costs. IBM. Retrieved Nov 2020, from ftp.software.ibm.com/software/rational/info/do-more/RAW14109USEN.pdf

[6] Souza, R., Rocha, L., Silva, F., \&amp; Machado, I. (2019). Investigating Agile Practices in Software Start-ups. Proceedings of the XXXIII Brazilian Symposium on Software Engineering - SBES 2019. doi:10.1145/3350768.3350786

[7] Melegati, J. (2018). What influences software start-ups to use lean start-up? Proceedings of the 19th International Conference on Agile Software Development Companion - XP '18. doi:10.1145/3234152.3314990

[8] Unterkalmsteiner, M., Abrahamsson, P., Wang, X., Nguyen-Duc, A., Shah, S., and Bajwa, S., 2016. Software Start-ups - A Research Agenda. [online] Core.ac.UK. Available at: <https://core.ac.uk/reader/297033577> [Accessed 28 November 2020].

[9] Paternoster, N., Giardino, C., Unterkalmsteiner, M., Gorschek, T., \& Abrahamsson, P. (2014). Software development in startup companies: A systematic mapping study. Information and Software Technology, 56(10), 1200-1218. doi:10.1016/j.infsof.2014.04.014

[10] Carmel, E. (1994). Time-to-completion in software package start-ups, Proceedings of the 27th Hawaii International Conference on System Sciences (HICSS).

[11] Zettel J., Maurer F., Münch J., Wong L. (2001) LIPE: A Lightweight Process for E-Business Start-up Companies Based on Extreme Programming. In: Bomarius F., Komi-Sirviö S. (eds) Product-Focused Software Process Improvement. PROFES 2001. Lecture Notes in Computer Science, vol 2188. Springer, Berlin, Heidelberg. https://doi.org/10.1007/3-540-44813-6_23

[12] Mirel, B. (2000, November). Product, process, and profit: the politics of usability in a software venture. ACM Journal of Computer Documentation, 24(4). https://doi.org/10.1145/353927.353928

[13] Tingling, P. (2007, July). in: Proceedings of the 12th International Conference on Human-computer interaction: Interaction Design and Usability (HCI). Extreme programming in action: a longitudinal case study, 242-251.

[14] Blank, S. (2013, May). Why the Lean Start-Up Changes Everything. Harvard Business Review. www.coolprofs.com/FilePub/c49e3d77-47e0-4649-b155-ae4d0a7fdaa0/COOLUp+2014+-+Lean+start-up+artikel.pdf

[15] C. Giardino, N. Paternoster, M. Unterkalmsteiner, T. Gorschek, and P. Abrahamsson, "Software Development in Start-up Companies: The Greenfield Start-up Model," in IEEE Transactions on Software Engineering, vol. 42, no. 6, pp. 585-604, 1 June 2016, DOI: 10.1109/TSE.2015.2509970.

[16] Riffat Naz, M. N. A. Khan, Muhammad Aamir,"Scrum-Based Methodology for Product Maintenance and Support", International Journal of Engineering and Manufacturing(IJEM), Vol.6, No.1, pp.10-27, 2016.DOI: 10.5815/ijem.2016.01.02

[17] Owe S.W and Yaacob M.H. (1996) "A Survey on Software Quality Assurance -A Malaysian Perspective". Proceedings of the 1996 IEEE Computer Society Information Systems Conference of New Zealand (ISCNZ'96) pp 154-163.

[18] Asad Masood Qazi, Sidra Shahzadi, Mamoona Humayun,"A Comparative Study of Software Inspection Techniques for Quality Perspective", International Journal of Modern Education and Computer Science(IJMECS), Vol.8, No.10, pp.9-16, 2016.DOI: 10.5815/ijmecs.2016.10.02

[19] Ali, W., Zia-Ur-Rehman, Badshah, A., \& Javed, A. (2015). Software Inspectionin Software Industry: A Pakistan's Perspective. I.J.Modern Education and Computer Science, DOI: 10.5815/ijmecs.2015.03.07

[20] Muhammad Asad Bin Khalid, Asim Farooq, Waqas Mahmood, (2021). "Communication Challenges for Distributed Teams", International Journal of Engineering and Manufacturing (IJEM), Vol.11, No.1, pp. 19-28, 2021. DOI: 10.5815/ijem.2021.01.03

[21] Farooqui, Sumeen, and Waqas Mahmood. "A survey of Pakistan's SQA Paractices: a Comparative Study." In 29th International Business Information Management Association Conference, Vienna, Austria. 2017.

[22] Qazi, Hareem, Zainab Javed, Sameen Majid, and Waqas Mahmood. "A Detailed Examination of the Enterprise Architecture Frameworks Being Implemented in Pakistan." International Journal of Modern Education \& Computer Science(IJMECS) 11, no. 9 (2019).

\section{Authors' Profiles}

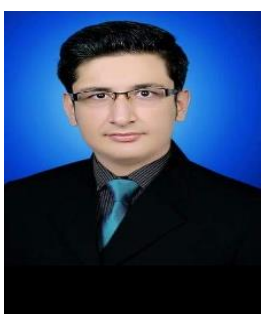

Santosh is a final year student of BS Computer Science at the Institute of Business Administration, Karachi. 


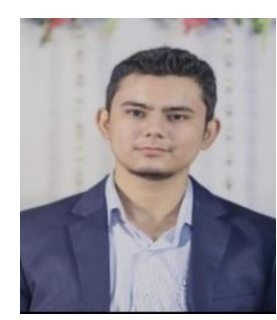

Saadullah Aleem is a Software Engineer currently working at Sastaticket. He got his Bachelors of Science degree in Computer Systems Engineering from Sir Syed University of Engineering \& Technology (SSUET) and is currently enrolled in an MS in Computer Science program at the Institute of Business Administration, Karachi.

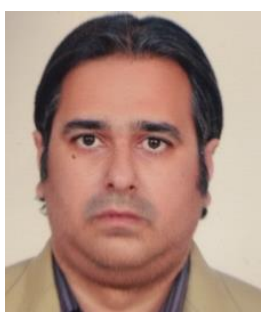

Waqas Mahmood is an Oxford Business Alumni (OBA) with transformational leadership skills for managing diverse, cross-functional teams. Waqas is an achievement-driven professional with more than 22 years of post-graduation work experience. He has been working across different functional areas including Governance, Banking, Technology Management, and Strategy. Have the ability to design and implement effective, strategies, implement new products, solutions and manage customers and resources to produce positive returns. Has published research work related to Corporate Governance, Strategic Management, Program Management, Project management, Analysis, Payment Systems Design and implementation of ERP System, Core Banking Application (CBA) implementations, E-banking, Cloud Computing, Data Mining, Big Data, Energy Audit, Financial \& Economic Analysis, Audits \& Reviews, and security Reviews. Waqas Mahmood has more than fifty (50) research publications to date.

How to cite this paper: Saadullah Aleem, Santosh, Waqas Mahmood, " Start-up failures due to Quality Failures ", International Journal of Engineering and Manufacturing (IJEM), Vol.11, No.2, pp. 1-13, 2021. DOI: 10.5815/ijem.2021.02.01 